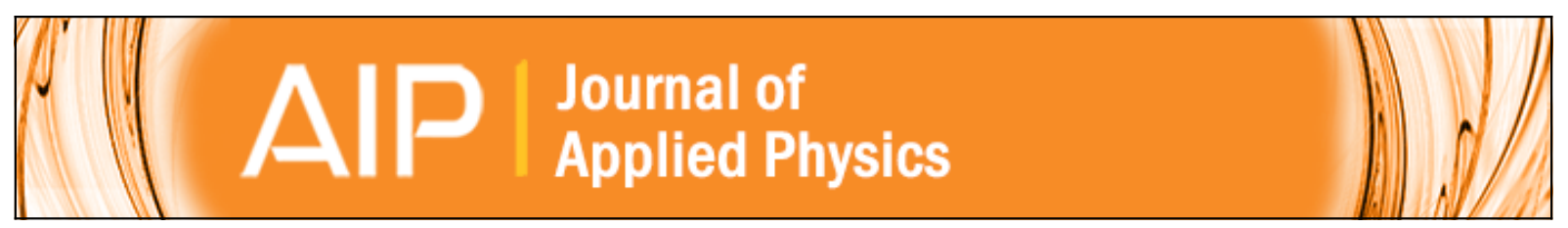

\title{
Improved formulation for Faraday rotation characterization
}

Jin-Wei Tioh, Robert J. Weber, and Mani Mina

Citation: Journal of Applied Physics 109, 07E334 (2011); doi: 10.1063/1.3554259

View online: http://dx.doi.org/10.1063/1.3554259

View Table of Contents: http://scitation.aip.org/content/aip/journal/jap/109/7?ver=pdfcov

Published by the AIP Publishing

\section{Articles you may be interested in}

Ultrafast terahertz Faraday rotation in graphene

J. Appl. Phys. 116, 214302 (2014); 10.1063/1.4903212

Optical Faraday rotation with graphene

J. Appl. Phys. 113, 17B529 (2013); 10.1063/1.4800949

Optical Faraday rotation

Am. J. Phys. 78, 270 (2010); 10.1119/1.3266970

Sagnac interferometric switch utilizing Faraday rotation

J. Appl. Phys. 105, 07E702 (2009); 10.1063/1.3058627

A desktop Faraday rotation instrument in the ultraviolet

Rev. Sci. Instrum. 79, 025109 (2008); 10.1063/1.2868789

\section{AIP $\mid$ APL Photonics}

APL Photonics is pleased to announce Benjamin Eggleton as its Editor-in-Chief

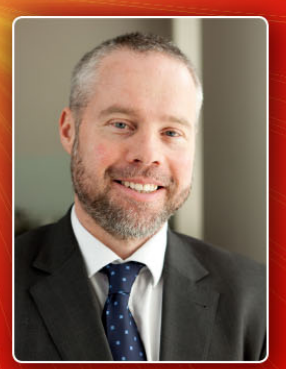




\title{
Improved formulation for Faraday rotation characterization
}

\author{
Jin-Wei Tioh, ${ }^{\text {a) }}$ Robert J. Weber, ${ }^{\text {b) }}$ and Mani Mina ${ }^{\mathrm{c})}$ \\ Department of Electrical and Computer Engineering, Iowa State University, Ames, Iowa 50011, USA
}

(Presented 17 November 2010; received 7 October 2010; accepted 22 November 2010; published online 15 April 2011)

\begin{abstract}
The analysis of complex structures consisting of fibers, films, birefringent, and magnetic materials is greatly aided by the availability of an analysis structure. Jones calculus is typically utilized in the course of such analyses. However, standard Jones calculus does not account for the effect of reflections. An improved formulation for the characterization of Faraday rotation that alleviates this shortcoming is reported here and is integral for the proper analysis of devices employing magneto-optic effects. (C) 2011 American Institute of Physics. [doi:10.1063/1.3554259]
\end{abstract}

The Faraday effect produces a rotation of the plane of polarization of light passing through magnetized media. It was first experimentally observed by Michael Faraday in 1845 in a piece of glass placed between the poles of the magnet and was the very first magneto-optical effect to be discovered. ${ }^{1}$ This Faraday rotation arises from the interaction between light passing through or reflecting from a medium and the electron spin due to the spin-orbit coupling. ${ }^{2,3}$ The Faraday effect has found a tremendous amount of applications: spin detection in spintronics, ${ }^{4-7}$ measurement of ellipticity and rotation angle to ascertain the Hall mobility and effective mass of free carriers, ${ }^{8-12}$ investigation of thin magnetic films and magnetic multi-layers, ${ }^{13,14}$ and pulsed current measurements. ${ }^{15}$

The authors have been actively pursuing photonic applications of magneto-optic materials, specifically transparent switches for all-optical networks that will enable interoperability between a multitude of bit-rates, protocols, and formats, as well as allowing the operators to better scale their networks to meet the subscriber requirements and enhance their services. ${ }^{16,17}$ In order to analyze a structure consisting of fibers, films, birefringent, and magnetic materials, it is helpful to have an analysis structure. Jones calculus is frequently utilized to perform such an analysis. ${ }^{18}$ However, standard Jones calculus does not account for the effect of reflections. In this paper, we describe an improved formulation for the characterization of Faraday rotation that alleviates this shortcoming and is integral for the proper analysis of devices employing magneto-optic effects.

The formalism of matrix notation is one of the most useful means of characterizing a device. Two representations that will be applied to characterizing structures at optical frequencies are the scattering $(\mathrm{S})$ and transmission $(\mathrm{T})$ matrices, ${ }^{19,20}$ which are more conventionally used in microwave and millimeter wave analyses.

Consider a hypothetical transmission line that has different propagation constants (PCs) and characteristic impedances (CIs) for each direction of propagation.

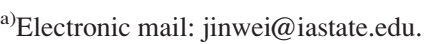

b)Electronic mail: weber@ iastate.edu.

${ }^{\mathrm{c})}$ Electronic mail: mmina@iastate.edu.
}

One might attempt to directly extend the transmission line equations for use with plane wave fields. However, in plane wave characterizations, there are two orthogonal axes for the electric field. For a particular device under test (DUT), there might also be coupling between the two orthogonal electric fields at the ports.

Several assumptions are made in the following analysis; waves in the fiber and magnetic material are plane waves the longitudinal distance through the material is short and modes generated in the interface between the fiber and material do not propagate down the fiber. A superposition of circularly polarized (CP) waves [clockwise $(\mathrm{CW})$ and counter-clockwise $(\mathrm{CCW})$ ] will be used to describe wave propagation in the ferrite material and in the interconnecting fibers since linearly polarized (LP) waves do not exist in anisotropic magnetic media.

Assuming plane wave travels in the $\mathrm{z}$ direction, there are four different CP (eight LP) waves traversing the magnetic region. In magnetic material, the two forward waves travel with different phase velocities as well as different CIs and likewise for the two reverse traveling waves. The CI and phase velocity of a $\mathrm{CW}$ wave traveling in the forward direction are the same as that of a $\mathrm{CCW}$ wave traveling in the reverse direction. An analysis via Maxwell's equations shows that the plane waves entering from an isotropic magnetic material into a magnetic material generate $\mathrm{CP}$ waves in the magnetic material with the coupling taking place at the boundary.

For port-to-port phase delay calculations, the input and output boundaries are considered to be at $z=0$. This describes a DUT that is inserted into a fiber at $\mathrm{z}=0$ as shown in Fig. 1. The wave coupling at the input will be described in terms of the continuity of tangential electric and magnetic fields. The CI and PC of the material has a subscript 1 for forward $\mathrm{CW}$ as well as reverse $\mathrm{CCW}$ waves and a subscript 2 for forward CCW and reverse CW waves.

Waves in the material will have subscripts $1-4$. A fourport $\mathrm{T}$ matrix will be formed. The physical input port will consist of two electromagnetic ports (one for each of the two orthogonal CP waves) and likewise for the physical output ports. The fiber material impedance will be chosen as the $\mathrm{T}$ matrix normalization impedance. It is necessary to use the 


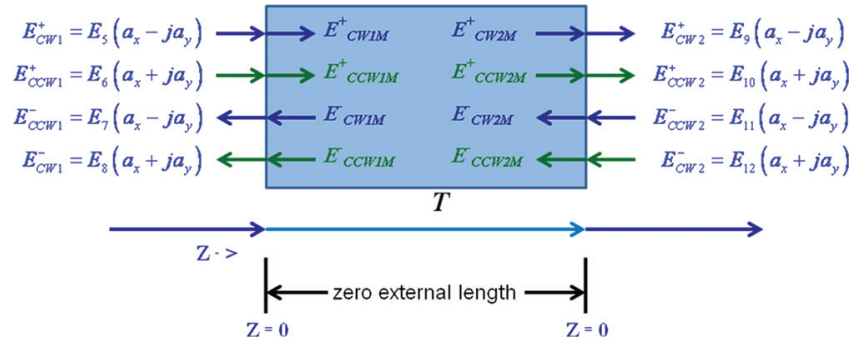

FIG. 1. (Color online) Notation for port-to-port phase delay calculations.

same normalization impedance on both ports to allow cascading of the matrices for analysis. Throughout this analysis, characteristic impedance will be used to mean material impedivity. The tangential electric and magnetic field values at the input [(1)-(4)] and output [(5)-(8)] boundaries are

$$
\begin{array}{cl}
\mathrm{E}_{\mathrm{CW} 1 \mathrm{M}}^{+}=\mathrm{E}_{1}\left(\mathrm{a}_{\mathrm{x}}-\mathrm{ja}_{\mathrm{y}}\right) & \mathrm{H}_{\mathrm{CW} 1 \mathrm{M}}^{+}=\frac{\mathrm{E}_{1}}{\eta_{1}}\left(\mathrm{ja}_{\mathrm{x}}+\mathrm{a}_{\mathrm{y}}\right) \\
\mathrm{E}_{\mathrm{CW} 1 \mathrm{M}}^{+}=\mathrm{E}_{2}\left(\mathrm{a}_{\mathrm{x}}+\mathrm{ja}_{\mathrm{y}}\right) & \mathrm{H}_{\mathrm{CWW} 1 \mathrm{M}}^{+}=\frac{\mathrm{E}_{2}}{\eta_{2}}\left(-\mathrm{ja}_{\mathrm{x}}+\mathrm{a}_{\mathrm{y}}\right), \\
\mathrm{E}_{\mathrm{CCW} 1 \mathrm{M}}^{-}=\mathrm{E}_{3}\left(\mathrm{a}_{\mathrm{x}}-\mathrm{ja}_{\mathrm{y}}\right) & \mathrm{H}_{\mathrm{CWW} 1 \mathrm{M}}^{-}=\frac{\mathrm{E}_{3}}{\eta_{1}}\left(-\mathrm{ja}_{\mathrm{x}}-\mathrm{a}_{\mathrm{y}}\right) \\
\mathrm{E}_{\mathrm{CW} 1 \mathrm{M}}^{-}=\mathrm{E}_{4}\left(\mathrm{a}_{\mathrm{x}}+\mathrm{ja}_{\mathrm{y}}\right) & \mathrm{H}_{\mathrm{CW} 1 \mathrm{M}}^{-}=\frac{\mathrm{E}_{4}}{\eta_{2}}\left(\mathrm{ja}_{\mathrm{x}}-\mathrm{a}_{\mathrm{y}}\right), \\
\mathrm{E}_{\mathrm{CW} 1}^{+}=\mathrm{E}_{5}\left(\mathrm{a}_{\mathrm{x}}-\mathrm{ja}_{\mathrm{y}}\right) & \mathrm{H}_{\mathrm{CW} 1}^{+}=\frac{\mathrm{E}_{5}}{\eta_{\mathrm{f}}}\left(\mathrm{ja}_{\mathrm{x}}+\mathrm{a}_{\mathrm{y}}\right) \\
\mathrm{E}_{\mathrm{CWW} 1}^{+}=\mathrm{E}_{6}\left(\mathrm{a}_{\mathrm{x}}+\mathrm{ja}_{\mathrm{y}}\right) & \mathrm{H}_{\mathrm{CWW} 1}^{+}=\frac{\mathrm{E}_{6}}{\eta_{\mathrm{f}}}\left(-\mathrm{ja}_{\mathrm{x}}+\mathrm{a}_{\mathrm{y}}\right),
\end{array}
$$

$$
\begin{aligned}
& \mathrm{E}_{\mathrm{CCW} 1}^{-}=\mathrm{E}_{7}\left(\mathrm{a}_{\mathrm{x}}-\mathrm{ja}_{\mathrm{y}}\right) \quad \mathrm{H}_{\mathrm{CCW} 1}^{-}=\frac{\mathrm{E}_{7}}{\eta_{\mathrm{f}}}\left(-\mathrm{ja}_{\mathrm{x}}-\mathrm{a}_{\mathrm{y}}\right) \\
& \mathrm{E}_{\mathrm{CW} 1}^{-}=\mathrm{E}_{8}\left(\mathrm{a}_{\mathrm{x}}+\mathrm{ja}_{\mathrm{y}}\right) \quad \mathrm{H}_{\mathrm{CW} 1}^{-}=\frac{\mathrm{E}_{8}}{\eta_{\mathrm{f}}}\left(\mathrm{ja}_{\mathrm{x}}-\mathrm{a}_{\mathrm{y}}\right), \\
& \mathrm{E}_{\mathrm{CW} 2 \mathrm{M}}^{+}=\mathrm{E}_{1}\left(\mathrm{a}_{\mathrm{x}}-\mathrm{ja}_{\mathrm{y}}\right) \mathrm{e}^{-\mathrm{j} \beta_{1} \mathrm{~L}} \quad \mathrm{H}_{\mathrm{CW} 2 \mathrm{M}}^{+}=\frac{\mathrm{E}_{1}}{\eta_{1}}\left(\mathrm{ja}_{\mathrm{x}}+\mathrm{a}_{\mathrm{y}}\right) \mathrm{e}^{-\mathrm{j} \beta_{1} \mathrm{~L}} \\
& \mathrm{E}_{\mathrm{CCW} 2 \mathrm{M}}^{+}=\mathrm{E}_{2}\left(\mathrm{a}_{\mathrm{x}}+\mathrm{ja}_{\mathrm{y}}\right) \mathrm{e}^{-\mathrm{j} \beta_{2} \mathrm{~L}} \quad \mathrm{H}_{\mathrm{CCW} 2 \mathrm{M}}^{+}=\frac{\mathrm{E}_{2}}{\eta_{2}}\left(-\mathrm{ja}_{\mathrm{x}}+\mathrm{a}_{\mathrm{y}}\right) \mathrm{e}^{-\mathrm{j} \beta_{2} \mathrm{~L}}, \\
& \mathrm{E}_{\mathrm{CCW} 2 \mathrm{M}}^{-}=\mathrm{E}_{3}\left(\mathrm{a}_{\mathrm{x}}-\mathrm{ja} \mathrm{a}_{\mathrm{y}}\right) \mathrm{e}^{\mathrm{j} \beta_{1} \mathrm{~L}} \quad \mathrm{H}_{\mathrm{CCW} 2 \mathrm{M}}^{-}=\frac{\mathrm{E}_{3}}{\eta_{1}}\left(-\mathrm{ja} \mathrm{a}_{\mathrm{x}}-\mathrm{a}_{\mathrm{y}}\right) \mathrm{e}^{\mathrm{j} \beta_{1} \mathrm{~L}} \\
& \mathrm{E}_{\mathrm{CW} 2 \mathrm{M}}^{-}=\mathrm{E}_{4}\left(\mathrm{a}_{\mathrm{x}}+\mathrm{ja} \mathrm{a}_{\mathrm{y}}\right) \mathrm{e}^{\mathrm{j} \beta_{2} \mathrm{~L}} \quad \mathrm{H}_{\mathrm{CW} 2 \mathrm{M}}^{-}=\frac{\mathrm{E}_{4}}{\eta_{2}}\left(\mathrm{ja}_{\mathrm{x}}-\mathrm{a}_{\mathrm{y}}\right) \mathrm{e}^{\mathrm{j} \beta_{2} \mathrm{~L}}, \\
& \mathrm{E}_{\mathrm{CW} 2}^{+}=\mathrm{E}_{9}\left(\mathrm{a}_{\mathrm{x}}-\mathrm{ja}_{\mathrm{y}}\right) \quad \mathrm{H}_{\mathrm{CW} 2}^{+}=\frac{\mathrm{E}_{9}}{\eta_{\mathrm{f}}}\left(\mathrm{ja}_{\mathrm{x}}+\mathrm{a}_{\mathrm{y}}\right) \\
& \mathrm{E}_{\mathrm{CCW} 2}^{+}=\mathrm{E}_{10}\left(\mathrm{a}_{\mathrm{x}}+\mathrm{ja}_{\mathrm{y}}\right) \quad \mathrm{H}_{\mathrm{CCW} 2}^{+}=\frac{\mathrm{E}_{10}}{\eta_{\mathrm{f}}}\left(-\mathrm{ja}_{\mathrm{x}}+\mathrm{a}_{\mathrm{y}}\right), \\
& \mathrm{E}_{\mathrm{CCW} 2}^{-}=\mathrm{E}_{11}\left(\mathrm{a}_{\mathrm{x}}-\mathrm{ja}_{\mathrm{y}}\right) \quad \mathrm{H}_{\mathrm{CCW} 2}^{-}=\frac{\mathrm{E}_{11}}{\eta_{\mathrm{f}}}\left(-\mathrm{ja}_{\mathrm{x}}-\mathrm{a}_{\mathrm{y}}\right) \\
& \mathrm{E}_{\mathrm{CW} 2}^{-}=\mathrm{E}_{12}\left(\mathrm{a}_{\mathrm{x}}+\mathrm{ja}_{\mathrm{y}}\right) \quad \mathrm{H}_{\mathrm{CW} 2}^{-}=\frac{\mathrm{E}_{12}}{\eta_{\mathrm{f}}}\left(\mathrm{ja}_{\mathrm{x}}-\mathrm{a}_{\mathrm{y}}\right),
\end{aligned}
$$

where unit vectors $\overrightarrow{\mathrm{a}}$ are in the $\mathrm{x}$ or $\mathrm{y}$ direction, $\eta_{\mathrm{f}}$ is the fiber material $\mathrm{CI}, \eta_{1}$ is the magnetic material $\mathrm{CI}$ in the forward $\mathrm{CW}$ direction, $\eta_{2}$ is the magnetic material $\mathrm{CI}$ in the forward $\mathrm{CCW}$ direction, and $\mathrm{L}$ is the length of the magnetic material.

Applying the boundary conditions at the input (9) and output (10) yields

The input and output waves are related using forward $\mathrm{T}$ parameters as

$$
\left.\left.\left(\left(\begin{array}{c}
\mathrm{E}_{5} \\
\mathrm{E}_{6}
\end{array}\right)\right)=\left(\begin{array}{ll}
\left(\mathrm{T}_{\mathrm{UL}}\right) & \left(\mathrm{T}_{\mathrm{UR}}\right) \\
\left(\mathrm{T}_{\mathrm{LL}}\right) & \left(\mathrm{T}_{\mathrm{LR}}\right)
\end{array}\right)\left(\begin{array}{c}
\mathrm{E}_{9} \\
\mathrm{E}_{10}
\end{array}\right)\right)\left(\begin{array}{c}
\mathrm{E}_{11} \\
\mathrm{E}_{8}
\end{array}\right)\right)
$$

With the source on the input port and terminations on the output port, we obtain the relationships in (12). Conversely with the source on the output port and terminations on the input port, we obtain the relationships in (13).

$$
\begin{aligned}
\left(\begin{array}{c}
E_{9} \\
E_{10}
\end{array}\right) & =\left(T_{U L}\right)^{-1}\left(\begin{array}{l}
E_{5} \\
E_{6}
\end{array}\right) \\
\left(\begin{array}{c}
E_{7} \\
E_{8}
\end{array}\right) & =\left(T_{\mathrm{LL}}\right)\left(T_{\mathrm{UL}}\right)^{-1}\left(\begin{array}{l}
E_{5} \\
E_{6}
\end{array}\right),
\end{aligned}
$$

$$
\begin{aligned}
& \left(\begin{array}{c}
\mathrm{E}_{9} \\
\mathrm{E}_{10}
\end{array}\right)=-\left(\mathrm{T}_{\mathrm{UL}}\right)^{-1}\left(\mathrm{~T}_{\mathrm{UR}}\right)\left(\begin{array}{c}
\mathrm{E}_{11} \\
\mathrm{E}_{12}
\end{array}\right) \\
& \left(\begin{array}{c}
\mathrm{E}_{7} \\
\mathrm{E}_{8}
\end{array}\right)=\left(-\left(\mathrm{T}_{\mathrm{LL}}\right)\left(\mathrm{T}_{\mathrm{UL}}\right)^{-1}\left(\mathrm{~T}_{\mathrm{UR}}\right)+\left(\mathrm{T}_{\mathrm{LR}}\right)\right)\left(\begin{array}{l}
\mathrm{E}_{11} \\
\mathrm{E}_{12}
\end{array}\right) .
\end{aligned}
$$

The input and output waves are related using reverse $\mathrm{T}$ parameters as 


$$
\left.\left(\begin{array}{c}
\mathrm{E}_{9} \\
\mathrm{E}_{10}
\end{array}\right)=\left(\begin{array}{ll}
\left(\mathrm{T}_{\mathrm{R}-\mathrm{UL}}\right) & \left(\mathrm{T}_{\mathrm{R}-\mathrm{UR}}\right) \\
\left(\mathrm{E}_{11}\right. \\
\mathrm{E}_{12}
\end{array}\right)\right)\left(\begin{array}{c}
\left(\begin{array}{c}
\mathrm{E}_{5} \\
\mathrm{E}_{6}
\end{array}\right) \\
\left(\begin{array}{c}
\mathrm{T}_{7} \\
\mathrm{E}_{8}-\mathrm{LR}
\end{array}\right)
\end{array}\right),
$$

With the source on the input port and terminations on the output port, we obtain the relationships in (15). Conversely with the source on the output port and terminations on the input port, we obtain the relationships in (16).

$$
\begin{aligned}
\left(\begin{array}{c}
E_{7} \\
E_{8}
\end{array}\right)=-\left(T_{R-L R}\right)^{-1}\left(T_{R-L L}\right)\left(\begin{array}{c}
E_{5} \\
E_{6}
\end{array}\right) \\
\left(\begin{array}{c}
E_{9} \\
E_{10}
\end{array}\right)=\left(\left(T_{R-U L}\right)-\left(T_{R-U R}\right)\left(T_{R-L R}\right)^{-1}\left(T_{R-L L}\right)\right)\left(\begin{array}{c}
E_{5} \\
E_{6}
\end{array}\right), \\
\left(\begin{array}{c}
E_{7} \\
E_{8}
\end{array}\right)=\left(T_{R-L R}\right)^{-1}\left(\begin{array}{c}
E_{11} \\
E_{12}
\end{array}\right) \\
\left(\begin{array}{c}
E_{9} \\
E_{10}
\end{array}\right)=\left(T_{R-U R}\right)\left(T_{R-L R}\right)^{-1}\left(\begin{array}{c}
E_{11} \\
E_{12}
\end{array}\right) .
\end{aligned}
$$

The $\mathrm{S}$ matrix for an $\mathrm{x}$ axis polarized wave can be determined from adding the appropriate wave pairs. Likewise the $\mathrm{S}$ matrix for a $\mathrm{y}$ axis polarized wave can be determined from subtracting the appropriate wave pairs. However, since a single axis oriented input can give a dual axis output, the concept of the $\mathrm{S}$ matrix would need to be extended based on its use similar to the concept of common and differential mode $\mathrm{S}$ matrices. Likewise, a single axis oriented input can give reflections back from the input on both the $\mathrm{x}$ and $\mathrm{y}$ axes.

Using $\mathrm{a}$ and $\mathrm{b}$ variables from $\mathrm{S}$ parameter notation, the $\mathrm{T}$ matrix can be used to relate these variables. However, an additional comment is necessary. In the $S$ parameter notation, a variables represent quantities incident on a port while b variables represent quantities reflected from a port. Since the preceding analysis has been developed using modes and direction, it is necessary to point out that the top part of submatrices represent one mode pair and the bottom part of submatrices represent the other mode pair. Therefore some a and/or b variables will have opposite subscripts (CW and $\mathrm{CCW}$ ) because some of them are in the positive $\mathrm{z}$ direction and some in the negative $\mathrm{z}$ direction.

The $\mathrm{S}$ matrix of a non-reciprocal transmission line with two different CP waves is given below. Notice that transmission is between the same senses of polarization but reflection is between opposite senses of polarization.

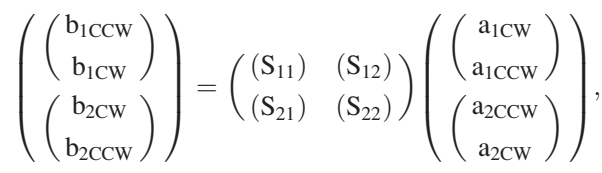

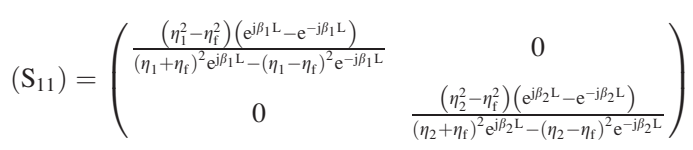

$$
\begin{aligned}
& \left(\mathrm{S}_{12}\right)=\left(\begin{array}{cc}
\frac{4 \eta_{\mathrm{f}} \eta_{1}}{\left(\eta_{1}+\eta_{\mathrm{f}}\right)^{2} \mathrm{e}^{\mathrm{j} \beta_{1}} \mathrm{~L}-\left(\eta_{1}-\eta_{\mathrm{f}}\right)^{2} \mathrm{e}^{-\mathrm{j} \beta_{1} \mathrm{~L}}} & 0 \\
0 & \frac{4 \eta_{\mathrm{f}} \eta_{2}}{\left(\eta_{2}+\eta_{\mathrm{f}}\right)^{2} \mathrm{e}^{\mathrm{j} \beta_{2} \mathrm{~L}}-\left(\eta_{2}-\eta_{\mathrm{f}}\right)^{2} \mathrm{e}^{-\mathrm{j} \beta_{2} \mathrm{~L}}}
\end{array}\right)
\end{aligned}
$$

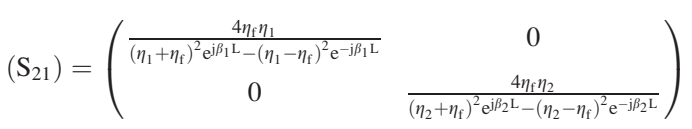

$$
\begin{aligned}
& \left(\mathrm{S}_{22}\right)=\left(\begin{array}{cc}
\frac{\left(\eta_{1}^{2}-\eta_{\mathrm{f}}^{2}\right)\left(\mathrm{e}^{\mathrm{j} \beta_{1} \mathrm{~L}}-\mathrm{e}^{-\mathrm{j} \beta_{1} \mathrm{~L}}\right)}{\left(\eta_{1}+\eta_{\mathrm{f}}\right)^{2} \mathrm{e}^{\mathrm{i} \beta_{1} \mathrm{~L}}-\left(\eta_{1}-\eta_{\mathrm{f}}\right)^{2} \mathrm{e}^{-\mathrm{j} \beta_{1} \mathrm{~L}}} & 0 \\
0 & \frac{\left(\eta_{2}^{2}-\eta_{\mathrm{f}}^{2}\right)\left(\mathrm{e}^{\mathrm{i} \beta_{2}} \mathrm{~L}-\mathrm{e}^{-\mathrm{j} \beta_{2} \mathrm{~L}}\right)}{\left(\eta_{2}+\eta_{\mathrm{f}}\right)^{2} \mathrm{e}^{\mathrm{\beta} \beta_{2} \mathrm{~L}}-\left(\eta_{2}-\eta_{\mathrm{f}}\right)^{2} \mathrm{e}^{-\mathrm{j} \beta_{2} \mathrm{~L}}}
\end{array}\right)
\end{aligned}
$$

The effect of an air gap or other inserted material having a different $\mathrm{CI}$ from that of the fiber can be accommodated using the four-port $\mathrm{T}$ matrix for two $\mathrm{CP}$ traveling waves. This matrix can be generated from the magnetic material matrix assuming that the material constants are the same in both directions.

When using a linear excitation, for example, an $\mathrm{x}$ axis excitation, $E_{5}$ and $E_{6}\left(a_{1 C W}=a_{1 C C W}\right)$ would be set equal to each other. For a $\mathrm{y}$ axis excitation, $\mathrm{E}_{5}$ and $\mathrm{E}_{6}$ would be set to the negative of each other $\left(\mathrm{a}_{1 \mathrm{CW}}=-\mathrm{a}_{1 \mathrm{CCW}}\right)$. Similarly, when determining the axis of rotation for the polarization, the tangent ratio of the appropriate values of the port excitations would be used.

A tractable formulation for analyzing complex structures consisting of fibers, films, birefringent, and magnetic materials is reported. This addresses the shortcomings of standard Jones calculus and enables a proper analysis of magneto-optic devices. For physical arrangements where higher-order modes are appreciable, the formalism would need to be extended to accommodate those modes.

${ }^{1}$ J. D. Krauss and K. R. Carver, Electromagnetics (McGraw-Hill, New York, 1973).

${ }^{2}$ P. S. Pershan, J. Appl. Phys. 38, 1482 (1967).

${ }^{3}$ F. J. Kahn, P. S. Pershan, and J. P. Remeika, Phys. Rev. 186, 891 (1969).

${ }^{4}$ J. H. Versluis et al. Phys. Rev. B. 80, 193303 (2009).

${ }^{5}$ R. Mansell et al. IEEE Trans. Magn. 44, 2666 (2008).

${ }^{6}$ S. Ghosh et al. Appl. Phys. Lett. 92, 162109 (2008).

${ }^{7}$ J. M. Kikkawa and D. D. Awschalom, Phys. Rev. Lett. 80, 4313 (1998).

${ }^{8}$ E. Palik and J. Furdyna, Rep. Prog. Phys. 33, 1193 (1970).

${ }^{9}$ Y. I. Ukhanov, Sov. Phys. Usp. 16, 236 (1973).

${ }^{10}$ J. Furdyna and S. Broersma, Phys. Rev. 120, 1995 (1960).

${ }^{11}$ R. R. Rau and M. E. Caspari, Phys. Rev. 100, 632 (1955).

${ }^{12}$ J. K. Furdyna and M. E. Brodwin, Phys. Rev. 124, 740 (1961).

${ }^{13}$ A. K. Zvezdin and V. A. Kotov, Modern Magnetooptics and Magnetooptical Materials (IOP, Bristol, UK, 1997).

${ }^{14}$ Y. S. Dadoenkova et al. Appl. Phys. Lett. 97, 011901 (2010).

${ }^{15}$ A. D. White, G. B. McHale, and D. A. Goerz, IEEE PPC, 1358 (2010).

${ }^{16}$ J.-W. Tioh, M. Mina, and R. J. Weber, IEEE Trans. Magn. 46, 2474 (2010).

${ }^{17}$ R. Bahuguna, J. Tioh, M. Mina, and R. J. Weber, IEEE Trans. Magn. 42, (2006).

${ }^{18}$ A. Gerrard and J. M. Burch, Introduction to Matrix Methods in Optics (Dover Publications Inc, New York, 1994), p. 212.

${ }^{19}$ K. Kurokawa, IEEE Trans. Microwave Theory Tech. 13, 194 (1965).

${ }^{20}$ E. W. Matthews, IEEE Trans. Microwave Theory Tech. 3, 21 (1955). 